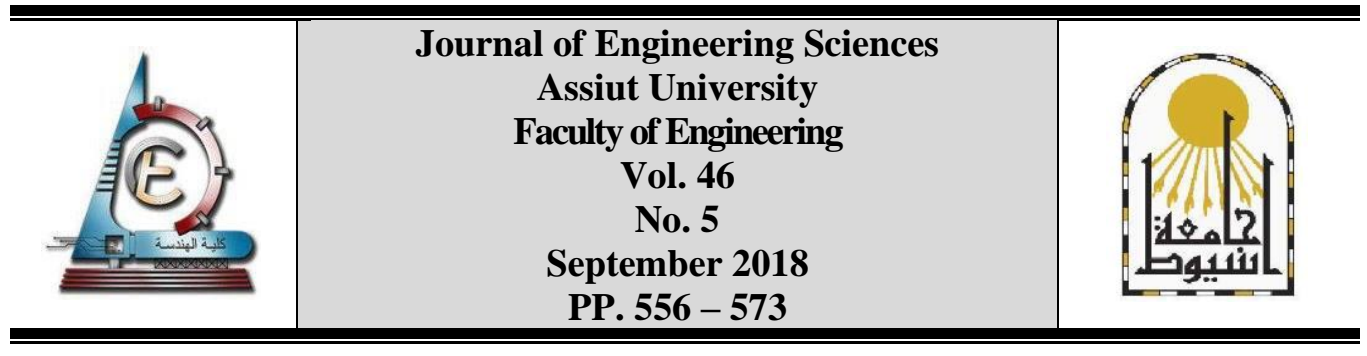

\title{
CHARACTERIZATION OF AN EXPERIMENTAL FACILITY FOR BUBBLING FLUIDIZED BED COMBUSTOR
}

\author{
Hamdy M. Shafey ${ }^{1, *}$, Walid J. Al-Nahari ${ }^{2}$, \\ Emad H. El-Zohri ${ }^{3}$ and Aliaa O. Abbas ${ }^{4}$ \\ 1, 2, 4 Department of Mech. Eng., Faculty of Engineering, Assiut University, Assiut Egypt \\ ${ }^{3}$ Electrical Department, Faculty of Industrial Education, Sohag University
}

Received 2 July 2018; Accepted 21 July 2018

\begin{abstract}
Fluidized bed technology offers an attractive way for energy production with clean environment by the combustion of even low-grade waste derived fuels (WDF). This paper reports experimental results concerning the characterization of a small-scale bubbling atmospheric fluidized bed combustor with WDF batch feeding. The combustor having $0.215 \mathrm{~m}$ inner diameter and $1.88 \mathrm{~m}$ height is equipped with a packed-bed sandwich-type fluidizing air distributor. The experimental fluidized bed combustor (EFBC) is provided with facility items necessary for the operation, control, and measurements. Results of the measured fluidized bed pressure drop and temperature were investigated for cold flow, hot flow, and combustion tests during the characterization procedure. The results of these tests clearly indicated the good fluidization characteristics inherent to wellcontrolled operation of the EFBC facility. The characterization tests also indicated the reproducible and safe operation characteristics of the EFBC facility without appreciable leakage of fluidizing air and exhaust gases. Moreover, the obtained uniformity of the fluidized bed temperature together with the high estimated values of bed-to-immersed cooling coil heat transfer coefficient, added more evidence on the good combustion characteristics of the investigated EFBC facility.
\end{abstract}

Keywords: Characterization, Experimental facility, Fluidized bed technology, Bubbling bed, and Combustion of waste-derived fuels

\section{Introduction}

Problems of energy and environment have become subjects of widespread interest since the occurrence of energy crisis resulting from October 1973 war. The search for practical solutions of these problems has motivated the energy production from cheap and available new energy sources in the form of combustible solid materials. Such materials are usually of low-grade properties and are referred to as waste-derived fuels (WDF). There is a great deal with the utilization of large WDF quantities annually produced in Egypt. This task has been planned to be done via research works dealing on the topic of reducing the accompanied environmental

\footnotetext{
* Corresponding author.

E-mail address: hamdy.shafei@eng.au.edu.eg
} 
problems [1-3]. These large quantities include naturally-available, poor quality coals with high sulfur content [4], tar sands, and oil shales. In addition, industrial, agricultural, and municipal solid wastes are considered WDF as they have substantial calorific values. The combustion of solid fuels as well as WDF includes complicated physical and chemical reaction processes. This complexity makes the conventional WDF combustion methods, in general, technically inefficient. Also, much air pollution is produced due to the high emission rates of sulfur oxides $\left(\mathrm{SO}_{\mathrm{x}}\right)$ and nitrogen oxides $\left(\mathrm{NO}_{\mathrm{x}}\right)$, associated with the conventional WDF combustion. On the other hand, fluidized bed combustion offers a new method which is technically efficient and environmentally clean with pollution emission rates well below the EPA (U. S. Environmental Protection Agency) standards [5]. Moreover, increased heat transfer rates to the coolant tubes immersed in the fluidized bed, lead to economically acceptable smaller combustor and boiler sizes [6 and 7]. A Fluidized bed combustor is classified as a multi-phase system in which multi-solid fuels can be fed and combusted in a fluidized bed of particulate inert solid material (e.g. sand) [8 and 9]. The fluidized bed of particles originally is fixed and rests vertically on a porous base inside a container. Then, this fixed bed is maintained in a state of fluidization by upward flow of air required for combustion [10]. Extensive reviews have been published on the fundamentals, status, and developments of fluidized bed technology in relation to the WDF combustion in an environmentally acceptable manner [1, 11 and 12]. On the world scale, exhaustive research works on experimental small-scale and large-scale fluidized bed combustion facilities have been carried out in the last three decades. Examples of these research works [13-22] have used different WDF materials including oil shale, lignite, lowgrade coals, industrial wastes, and agricultural wastes. The fluidized bed combustion of these waste materials was done in different experimental facilities with fluidized bed combustor cross section areas ranging from $0.008 \mathrm{~m}^{2}$ to $36 \mathrm{~m}^{2}$ and corresponding heights ranging from 1.5 $\mathrm{m}$ to $16 \mathrm{~m}$. The results of these research works have proven that the fluidized bed combustion could be applied successfully to a wide variety of waste-derived fuels. On the national scale, Shafey and others [23] have reported the results of an experimental research work on fluidized bed WDF combustion for clean heat and power generation. This research work was a part of linkage energy project between Assiut University and American Kansas State University $(\mathrm{KSU})$. The research work has been done on a bench-scale facility involving $0.1 \mathrm{~m}$ inner diameter experimental fluidized bed combustor (EFBC). The EFBC facility of the energy project was a preliminary one employed to provide some useful information regarding its design, manufacturing, and assembly. More important issue of getting experience with the complicated EFBC operation and control was intended together with different labors training within this field. In brief, the fluidized bed combustors are versatile multi-phase systems for thermal energy production with clean environment from a wide variety of fuels derived from waste materials. In addition, the published results of the exhaustive research works provide a wide scope experience and guidance covering many design aspects for well-operating WDF fluidized-bed combustors. However, there remain some challenges to overcome, and large number of issues requires further investigation for efficient design and optimum operation. These important design and operation characteristics are vitally needed for commercialization of the fluidized bed combustors before reaching an acceptable level of marketability. Such commercialization procedure has to be supported by a proper characterization of efficiently designed EFBC facilities. The characterization ensures the good fluidization and combustion characteristics of the whole EFBC facility prior to the long run operation.

The objective of this paper is to carry out an experimental research work on the characterization of a small scale $0.215 \mathrm{~m}$ inner diameter and $1.88 \mathrm{~m}$ height experimental 
fluidized bed combustor (EFBC). The combustor operates with WDF batch feeding in a bubbling atmospheric fluidized bed of sand particles. The specially-designed EFBC components have been manufactured in the workshops of the Faculty of Engineering. The combustor components have been assembled and erected together its necessary facility items in the Combustion Laboratory of Department of Mechanical Engineering, Assiut University. The facility items including the measuring and control instrumentation provide electricity, compressed air for fluidization, and cooling water supplies in safe and good operating conditions. The characterization has been performed via cold flow, hot flow, and combustion tests. The goal of these tests is to ensure the good fluidization characteristics possessed by the present EFBC facility. These characteristics are strongly related to the hydrodynamics, heat transfer, and combustion of well-controlled EFBC operation.

\section{Experimental work}

\subsection{Main features of the EFBC facility}

The major present EFBC components were designed and constructed taking into consideration the variety and complexity of the real processes occurring during the WDF combustion in fluidized beds. These processes are complicated and usually governed by numerous analytical and empirical equations expressing hydrodynamics, thermodynamics and heat transfer of fluidized bed particles (inert matter + fuel + sorbent). However, a simple and realistic design of an experimental fluidized bed combustor (EFBC) could be achieved to match the available and limited laboratory supplies, equipment, and instrumentation. This design procedure was based on the accumulated paratactical and research experience of the authors [1, 3, 7, 16, 23 and 24] for more than thirty years in the field of the fluidized bed combustion. The designed major components of the combustor were fabricated, constructed and assembled together with the other items completing the EFBC facility. These items are important and required to operate the fluidized bed combustor. Figure 1 shows the main features of the present whole experimental fluidized bed combustor facility. The present EFBC facility was planned to operate in the bubbling atmospheric mode of fluidization. The EFBC core is the compressed air required for fluidization and combustion. The limited capacities (volume flow rate and pressure) of the available facility items producing compressed air (fan, blowers and compressors) affect the choice for the best EFBC operation. Therefore, the air-cooled compressor 1a together with the water-cooled compressor $\mathbf{1 b}$ was selected to produce the total compressed air required for the operation. The compressed air flows through the storage tanks 2 across controlling valves, with its volume flow rate and pressure measured by rotameters $\mathbf{3}$ and pressure gages $\mathbf{4}$, respectively. 


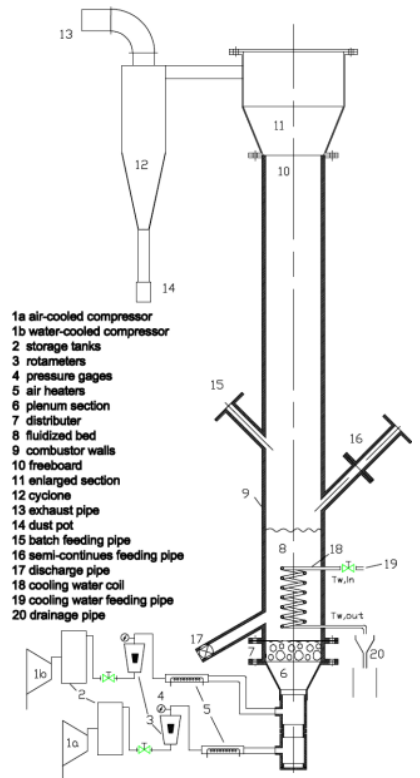

Fig. 1. Main items and components of the experimental fluidized bed combustor (EFBC) facility

The compressed air is then delivered to the facility items of electric heaters $\mathbf{5}$ for heating (if required). They are used to simulate fluidizing air preheating heat exchanger existing in the large-scale plants. The heated compressed air enters the first major component $\mathbf{6}$ of the EFBC, namely; plenum section. This section was designed so that compressed air coming from the air pipe with narrow flow passage area expands smoothly inside its inner space. Such expansion is usually accompanied with a pressure drop enabling primary uniform redistribution of the compressed air over the large flow passage area of the fluidized bed. The expanded fluidizing air is allowed to flow across the holes and pores of the second major component 7, namely; air distributor to the fluidized bed section 8. The air distributor consists of a packed bed of coarse sand sandwiched between two perforated plates, each with 200 holes of $2 \mathrm{~mm}$ diameter. The lower perforated plate is covered with three staggered metallic screens, each with $4 \mathrm{~mm}$ mesh size. The distributor which carries the load of the fluidized bed particles was designed and constructed to fulfill an important task. This task is to complete precisely the uniform distribution of the fluidizing air over the flow passage area of the fluidized bed section. The combination of the plenum section and the distributor provides the condition of high quality fluidization for the solid bed particles in section $\mathbf{8}$ represented by the nearly equal air velocity over the bed area. The fluidized bed particles are usually of inert material (e.g. sand) in which WDF combustion occurs. The fluidized bed particles are sometimes mixed with particles of sorbent matters (e.g. limestone) for the retention of sulfur oxides resulting from combustion of high sulfur content WDF. The fluidized bed particles are contained inside the third major EFBC component 9, namely; long cylindrical combustor walls. The circular combustor is $0.215 \mathrm{~m}$ inner diameter and $1.88 \mathrm{~m}$ height. It is constructed from high-temperature-resisting steel pipe with $16 \mathrm{~mm}$ thickness. The total height of the combustor walls provides sufficient space for the expansion of the bubbling fluidized bed. In addition, it provides a space for freeboard section 10 over the bubbling bed to allow combustion of the entrained fine particles of the unburned fuel inside the combustor. The outer EFBC hot surfaces extending up to the end of the freeboard section and down to the electric heaters surface are well thermally insulated using strips and strings of a high temperature thermal insulation. An enlarged section 
11 of the combustor walls, forming the fourth major EFBC component, is designed and constructed to reduce the velocity of the outward combustion gases. This leads to separating the fine particles from combustion gases and keeping them suspended to burn inside the combustor. The combustion products leaving the enlarged section are delivered to the cyclone 12 which is the fifth and final EFBC component. The cyclone serves in separating the fine solid ash particles form the gaseous combustion products. Clean flue gases are then exhausted to the atmosphere by the exhaust pipe 13. The separated fine solid ash particles are collected in the facility item, namely; dust pot 14. This item helps in quantitative and qualitative analysis of the solid combustion products. The bed particles of the inert material (sand) together with possible additive of sorbent material particles can be fed once in the form of a large charge with the required quantity (e.g. $10 \mathrm{~kg}$ ) to the combustor through the inclined pipe 15. This pipe is also used for batch feeding of WDF particles with large batches during combustion experiments. The inclined pipe $\mathbf{1 6}$ is used to for semi continuous operation of the fluidized bed combustor (if required). In this mode of operation, the WDF particles are fed through this pipe in successive small patches each for a small-time interval (e.g. 2 minutes). The feeding pipe $\mathbf{1 6}$ is provided with especial mechanism designed to allow easy two-stages transport of the small WDF patch by gravity. This mechanism is expected to give a safe and efficient operation, by preventing the outflow of combustion gasses from the feeding location. The bed residual material is removed from the combustor through the inclined pipe and valve 17. The facility items 18, 19 and 20 of the cooling water system are used for two purposes. The first purpose is to control the bed temperature in the combustor. The second purpose is to investigate the heat transfer between the fluidized bed and the immersed cooling coil. The cooling water with the required flow rate is allowed to circulate downward inside the cooling coil $\mathbf{1 8}$ through the feeding pipe 19. The cooling water is allowed to flow out the combustor through the drainage pipe $\mathbf{2 0}$ where its flowrate can be measured using stop watch and a pot with known volume. The cooling coil is constructed from stainless steel tube with $10 \mathrm{~mm}$ inner diameter, $12 \mathrm{~mm}$ outer diameter, and $5.6 \mathrm{~m}$ effective length. The cooling coil is shaped in a multi-turn form having the overall dimensions of $100 \mathrm{~mm}$ inner diameter, $124 \mathrm{~mm}$ outer diameter, and $210 \mathrm{~mm}$ height. It was fixed inside the combustor container in a vertical position $40 \mathrm{~mm}$ over the upper surface of the distributor. Both coil height and the vertical position allow total or partial immersion of the cooling coil in the bubbling fluidized bed depending on the bed conditions.

The temperatures at different locations in the combustor together with inlet and outlets temperatures $T_{w, i n}, T_{w, o u t}$ of the cooling water are measured using Type-K thermocouples. The temperature measurements can be read and stored using Data Acquisition System (Model NI cDAQ-9172 USB, National Instruments Corp., USA) linked with PC computer. The values of air pressure drop across the whole bed and at different bed locations together with that across the distributor are measured using water and mercury manometers. Figure 2 shows the axial vertical positions for temperature and pressure drop measuring probes along the bed and combustor height.

\subsection{Characterization tests}

Characterization tests of the EFBC facility were carried out to ensure the existence of the basic fluidization characteristics inherent to successful and controlled fluidized bed combustion of solid fuels. These characteristics are strongly linked to the hydrodynamics, heat transfer, and combustion events and processes in the EFBC bubbling and atmospheric fluidized bed. The characterization tests were grouped in the following manner. 


\subsubsection{Cold flow tests}

These tests were conducted mainly to investigate the possible effects of material and size of single bed particles, packed bed height or weight, and fluidizing air velocity on the hydrodynamic behavior of the fluidized bed. The tests were expected to be useful in examining the reproducibility of air flow and fluidization conditions for the inert bed material. They were also necessary to check air leakage defects (if any) at various EFBC connections.

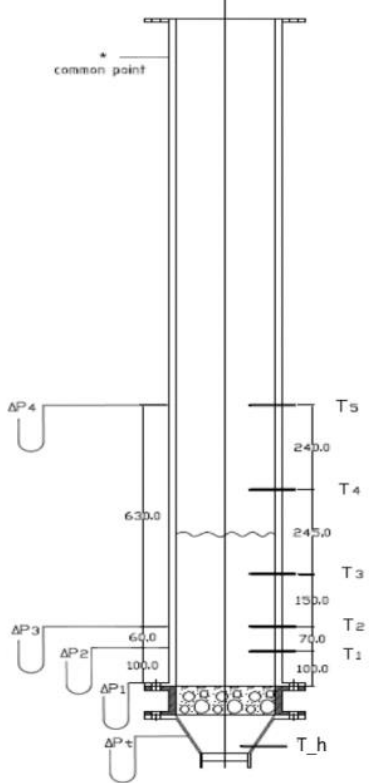

Fig. 2. Vertical positions for the bed temperature and pressure drop measuring probes

\subsubsection{Hot flow and combustion tests}

These tests were conducted to examine the extend of fluidizing air heating prior to combustion, and to investigate some related heat transfer and combustion characteristics. The tests also include trials for start-up and EFBC operation.

The materials used for the characterization tests were classified as follows:

a) bed inert particulate material (sand particles) where obtained from Manquabad mountainous area, $20 \mathrm{~km}$ north-west of Assiut city. A representative size range $\mathrm{d}=0.5-$ $0.705 \mathrm{~mm}$ of the sand particles could be selected according to sieve analysis. b) manufactured solid fuel particles (petroleum coke and charcoal) were selected with size range of $5.0-10.0 \mathrm{~mm}$. c) agricultural waste derived fuel particles (corncobs) were selected with average size of $10 \mathrm{~mm}$. d) sorbent material particles (limestone) were selected with size range of $1.25-1.6 \mathrm{~mm}$. The limestone sorbent material has to be used during the combustion of low grade fuel with high sulfur content if exists. It was obtained from Bani Khalid stone quarry at Samalut, $170 \mathrm{~km}$ north of Assiut city, with $54.71 \% \mathrm{Ca} O \mathrm{O}$ content.

\section{Results and discussion}

Experimental runs were performed on the present EFBC facility with different fluidized bed parameters and varying operating conditions. Measurements of the operating conditions were monitored with total duration of 50 hours. These Measurements were planned to cover the requirements for the two groups of characterization tests specified in the previous section. The corresponding results are expected to be satisfactory for clear 
information about the EFBC fluidization characteristics. The main measurements were the volume flow rate of the fluidizing air, the pressure drops across the distributor and the fluidized bed, and the temperature at different locations of the EFBC facility. They also included the inlet and outlet temperature of the cooling water together with its volume flow rate. These directly measured physical quantities were analyzed to derive other useful results regarding fluidized bed expansion and heat transfer to immersed cooling coil. The following discussion is carried out on different plots of both directly measured and derived results. These plots are classified according to the two groups of the characterization tests.

\subsection{Results for the cold flow tests}

Figures 3-9 show representative results on fluidization characteristics of fluidized bed under cold flow of fluidizing air. The pressure drop of the fluidizing air flow across the whole bed $\Delta P_{b}$ which is equal to the value $\Delta P_{1}$ measured by the first water manometer (see Fig. 2), is plotted versus the superficial velocity $u$ of the fluidizing air flow in Figs. 3 and 4 for different bed parameters. These are bed material, bed particle size, and packed bed height represented by the mass of the bed. The values of the superficial velocity $u$ were obtained from dividing the measured values of the fluidizing air volume flow rate at cold conditions by the effective crosssection area of the bed. The plots of the present results in Figs. 3 and 4 nearly show the same behavior of the typical plot reported by Kunii and Level spiel [10] for uniformly sized sand particles. The results shown in Figs. 3 and 4 indicate the existence of three main criteria for good fluidization of the bed particles. The first criterion is that the bed pressure drop $\Delta P_{b}$ increases with the fluidizing air velocity $u$, indicating the packed bed behavior. This behavior continues with little bed expansion until a specified value of the velocity $u_{m f}$ is reached at which $\Delta P_{b}$ attains an upper limit $\Delta P_{b, u p p e r}$. Increasing the velocity $u$ more than $u_{m f}$, the pressure drop $\Delta P_{b}$ remains nearly constant at the value of upper limit $\Delta P_{b, u p p e r}$. The second criterion is that the attained constant value of the pressure drop $\Delta P_{b, u p p e r}$ is equal to the corresponding calculated design value expressed as the actual bed weight $w_{b}$ divided by the effective bed cross-section area $a_{b}$. The third criterion is that the specified value $u_{m f}$ denotes the state of minimum fluidization above which the bed is fluidized in the bubbling regime. According to the above criteria, one can find that the results of Figs. 3 and 4 clearly verify the good quality of bubbling fluidization for the tested bed particles within the limited range of the fluidized air flow rate. This finding is evident when comparing the possible measured values of $\Delta P_{b, \text { upper }}$ and $u_{m f}$ representing the fluidization characteristics with the corresponding calculated design values. Table 1 shows the results of this comparison for different bed parameters. The design values of the minimum fluidization velocity $u_{m f}(0.47 \mathrm{~m} / \mathrm{s}, 0.91 \mathrm{~m} / \mathrm{s})$ were calculated using available correlations $[8,10]$ based on the upper limit of the particle size range. The measured values of the pressure drop $\Delta P_{b, \text { upper }}$ are in good agreement with the corresponding calculated values $w_{b} / a_{b}$ while acceptable agreement is shown for the values of the minimum fluidization velocity. The discrepancy between the measured and the calculated design values of $u_{m f}$ may be attributed to the effects of the bed internals, air flow fluctuations, flow control uncertainties, and measuring errors. 
Hamdy M. Shafey et al., Characterization of an experimental facility for bubbling fluidized .......

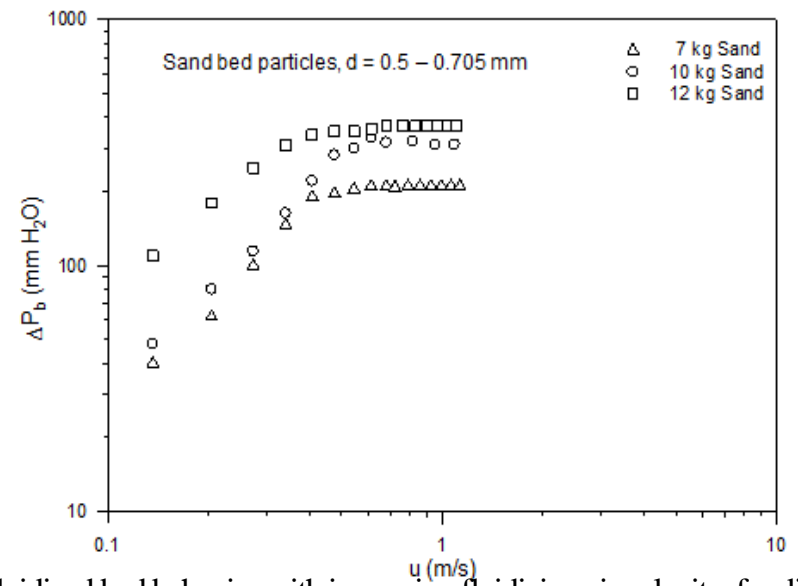

Fig. 3. Cold state fluidized bed behavior with increasing fluidizing air velocity, for different sand bed masses

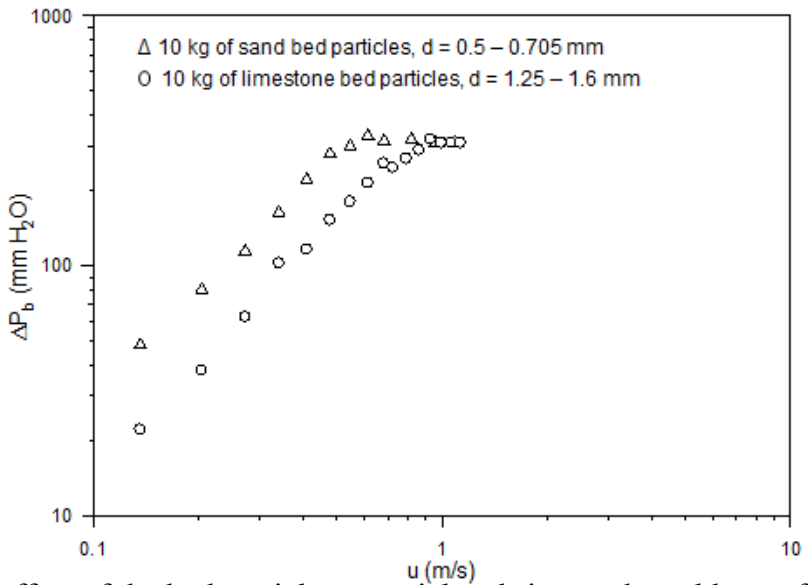

Fig. 4. Combined effect of the bed particles material and size on the cold state fluidized bed behavior

Table 1.

Comparison between the measured and calculated design values of fluidization characteristics

\begin{tabular}{|l|c|c|c|c|}
\hline \multicolumn{1}{|c|}{ Bed parameters } & $\begin{array}{c}\Delta P_{b, \text { upper }} \\
(\mathrm{mm} \mathrm{H} \mathrm{O})\end{array}$ & $\begin{array}{c}w_{b} / \mathrm{a}_{b} \\
\left(\mathrm{~mm} \mathrm{H} \mathrm{H}_{2} \mathrm{O}\right)\end{array}$ & $\begin{array}{c}\text { measured } u_{m f} \\
(\mathrm{~m} / \mathrm{s})\end{array}$ & $\begin{array}{c}\text { calculated } u_{m f} \\
(\mathrm{~m} / \mathrm{s})\end{array}$ \\
\hline $\begin{array}{l}7 \mathrm{~kg} \text { sand particle with size range d } \\
=0.5-0.705 \mathrm{~mm}\end{array}$ & 210 & 217 & 0.54 & 0.47 \\
\hline $\begin{array}{l}10 \mathrm{~kg} \text { sand particle with size range } \\
\mathrm{d}=0.5-0.705 \mathrm{~mm}\end{array}$ & 311 & 310 & 0.48 & 0.47 \\
\hline $\begin{array}{l}12 \mathrm{~kg} \text { sand particle with size range } \\
\mathrm{d}=0.5-0.705 \mathrm{~mm}\end{array}$ & 370 & 372 & 0.61 & 0.47 \\
\hline $\begin{array}{l}10 \mathrm{~kg} \text { limestone particle with size } \\
\text { range d }=1.25-1.6 \mathrm{~mm}\end{array}$ & 313 & 310 & 0.93 & 0.91 \\
\hline
\end{tabular}

More evidence on the good fluidization characteristics of the EFBC facility can be attained by examining the behavior of the fluidizing air pressure drop across the distributor. The quality of bubbling fluidization is strongly related to both type and design of the distributor. A hydrodynamic condition of sufficiently large pressure drop across the distributor is necessary to achieve a good fluidization quality indicated by the uniform distribution of the fluidizing air flow over the bed cross-section. Figure 5 shows the typical 
variation of the pressure drop $\Delta P_{d}$ across the distributor with the fluidizing air velocity $u$. The results shown can be used to check the above fluidization condition. The plotted values of the distributor pressure drop $\Delta P_{d}$ were measured using the mercury manometer used for measuring the total pressure drop $\Delta P_{t}$ (see Fig. 2) in the absence of the bed particles. The results of Fig. 5, generally, show larger values of the distributor pressure drop $\Delta P_{d}$ compared with corresponding values of the bed pressure drop $\Delta P_{b}$ in Figs. 3 and 4 at the same values of the air velocity $u$ above the $u_{m f}$ value. Despite of the deep fluidized beds together with the complicated sandwich type distributor design used in the present work, it is expected that the condition for good fluidization quality has been satisfied for the EFBC facility.

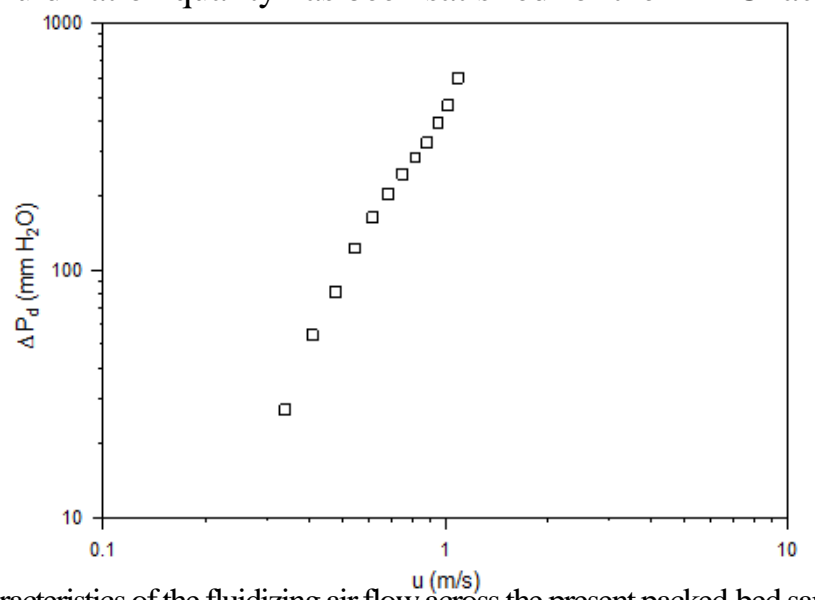

Fig. 5. Typical characteristics of the fluidizing air flow across the present packed-bed sandwich type distributor

Figures 6-9 show the results for the prediction and variation of the expanded bed height $L_{f}$ with the fluidizing air velocity $u$. Shown in Figs. 6-8 is an illustration for the application of the graphical method [23] used to predict the fluidized bed height for the three bed masses of sand particles. The method is based on the fact that the local bed pressure drop $\Delta P$ is linearly distributed over the vertical distance $z$ in the bed, for both packed bed and fluidization regimes. The bed pressure drop distribution for a specified value of the fluidizing air velocity, can be obtained and plotted using at least three measured values. Referring to Fig. 2, the three measured values were taken as the readings of the first water manometer $\Delta P_{1}, \Delta P_{2}$, and $\Delta P_{3}$. These readings were at fixed vertical distances of 0,100 $\mathrm{mm}$, and $160 \mathrm{~mm}$, respectively. The intersections of the straight lines fitting the plotted distributions, represent the values of the expanded bed height $L_{f}$ for different values of fluidizing air velocity $u$. Figure 9 shows the plots for the obtained values of the expanded bed height versus the fluidizing air velocity. The plots clearly show a continuous functional relationship between the expanded bed height $L_{f}$ and the fluidizing air velocity $u$. The nearly constant values of expanded bed height $L_{f}$ correspond to packed beds with little expansions. On the other hand, the linearly increasing behavior of $L_{f}$ represents expanding fluidized bed. The expansion of the fluidized bed is noticeable with the increase of the air velocity $u$ above the minimum fluidizing value $u_{m f}$. This is attributed to the formation and growth of air bubbles (pure gas) representing the increase of the fluidizing air flow above the flow associated with the minimum fluidization velocity $u_{m f}$. The expanded bed height $L_{f}$ is an important factor affecting the EFBC fluidization characteristics. As shown in Fig. 9, the larger is the mass of the bed particles, the deeper is the expanded bed height at the same fluidizing air velocity. Generally, it is preferable to keep the condition of shallow fluidized bed rather than the deep one. This condition 
maintains the more homogenous and stable behavior of the fluidized bed inherent to the operation in the bubbling regime. Also, the condition of shallow fluidized bed avoids the occurrence of some troubles associated with one of the other fluidization regimes such as slugging, turbulent, and fast regimes. In addition, the prediction of the expanded bed height represents a useful design tool to determine the suitable location and dimensions of the cooling coil or tubes to be immersed in the fluidized bed combustor.

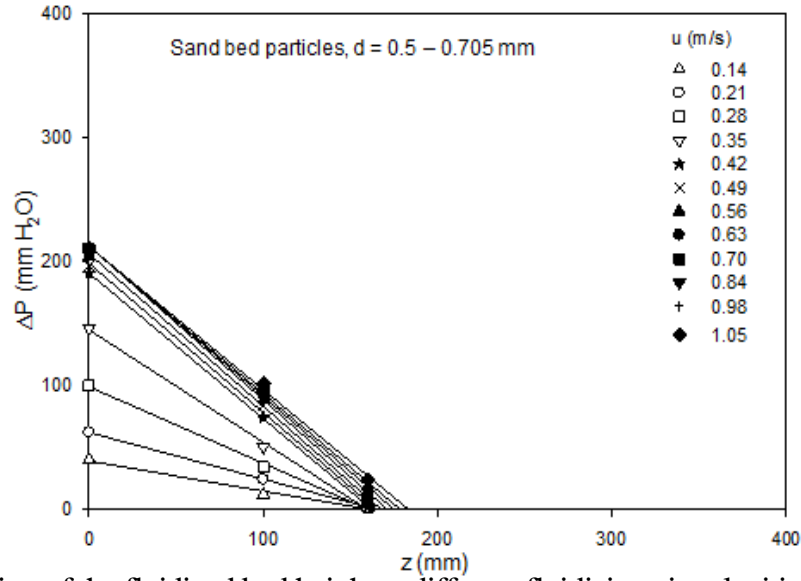

Fig. 6. Determination of the fluidized bed height at different fluidizing air velocities, for a bed mass of $7 \mathrm{~kg}$

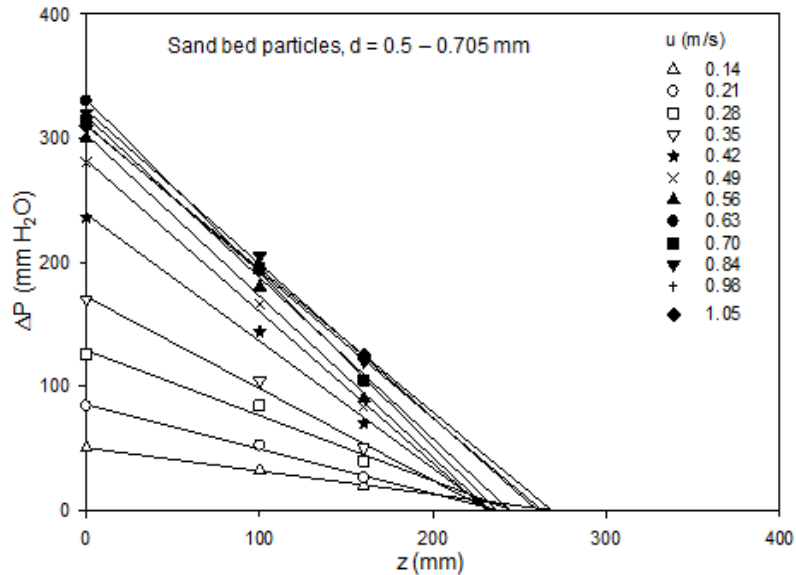

Fig. 7. Determination of the fluidized bed height at different fluidizing air velocities, for a bed mass of $10 \mathrm{~kg}$

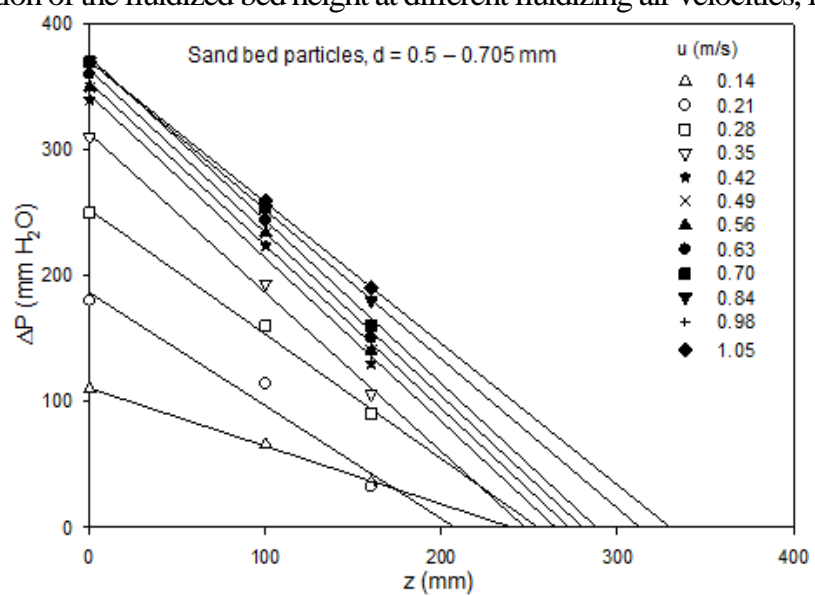

Fig. 8. Determination of the fluidized bed height at different fluidizing air velocities, for a bed mass of $12 \mathrm{~kg}$ 


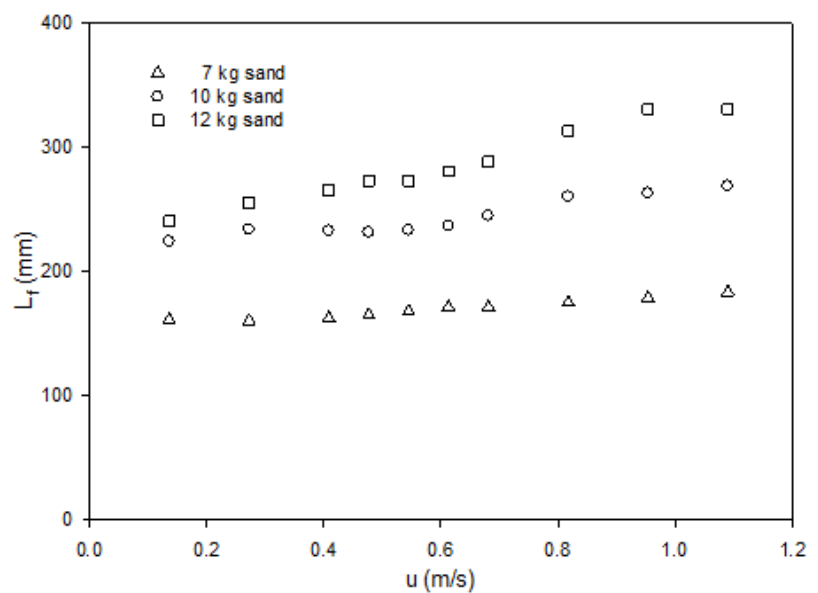

Fig. 9. Variation of the expanded bed height with the fluidizing air velocity for different sand bed masses (values estimated from Figs. 6-8)

The above discussion on the results of the cold flow tests can be extended to the high temperature conditions of the fluidized bed. These conditions are usually encountered with either hot flow of the fluidizing air or with the combustion of solid fuel in the fluidized bed. The extension of the discussion on the cold flow tests can be done in the following manner. The volume flow rate of the fluidizing air introduced to the connection of the EFBC facility is measured in the cold flow state. This volume expands when entering the high temperature fluidized bed. The resulting larger volume flow rate may be estimated by multiplying the measured cold flow value with the temperature ratio of the fluidized bed to that of the cold flow. This estimation is based on the ideal gas assumption of the air flow and neglecting the effect of pressure difference between the introduced air and the fluidized bed. The value of the hot state volume flow rate, by turn, is converted to a value of hot state fluidizing air velocity. Utilizing this velocity value with the plots shown in Figs. 3-9, one can obtain the fluidization characteristics for the high temperature fluidized bed. Also, it should be noted that the experimental runs of the cold flow tests were performed using frequent opening and closing steps regarding the compressed fluidizing air. These steps could be reproduced with safety conditions accompanied by stable and easy handling of the compressed air for fluidization. Moreover, the different compressed air piping and connections of the EFBC were checked and found to be almost in good sealing against possible leakage.

\subsection{Results for the hot flow and combustion tests}

Figures 10-14 show representative results of the high temperature behavior associated with hot flow and combustion tests. The tests were performed with the volume flow rate of the fluidizing air adjusted at a value of $0.019 \mathrm{~m}^{3} / \mathrm{s}$ under cold flow conditions. This value was sufficient to maintain the fluidized bed in the bubbling regime with the high temperature conditions. The volume flow rate was kept constant at the value of $0.019 \mathrm{~m}^{3} / \mathrm{s}$ for all hot flow and combustion tests, otherwise stated. The figures show the plots of measured temperatures $T_{1}-T_{5}$ at different locations of the fluidized bed (see Fig. 2) versus time, each for a duration of 40 minutes. The values of the measured temperature $T_{h}$ of the preheated fluidizing air entering the plenum section are also plotted for convenient discussion of the results. The plots in Figs. 11-14 describe the temperature histories for the trials of combustion start-up in the fluidized bed under different operating conditions. These plots are used for the main discussion on the fluidization characteristics during combustion tests. The results in Fig. 10, 
represent the temperature history during the heating-up of the EFBC walls in the absence of the fluidized bed particles. The heating-up was achieved using hot flow of preheated fluidizing air. The values of the measured temperatures shown in Fig. 10, are predicted to be useful for the comparison between the hot plug flow of the single gas phase (fluidizing air) and the well mixed two-phase (emulsion + gas bubbles) hot flow linked with high temperature fluidized bed. Therefore, the results of Fig. 10 represent a helpful tool supporting the main discussion on the results of Figs. 11-14.

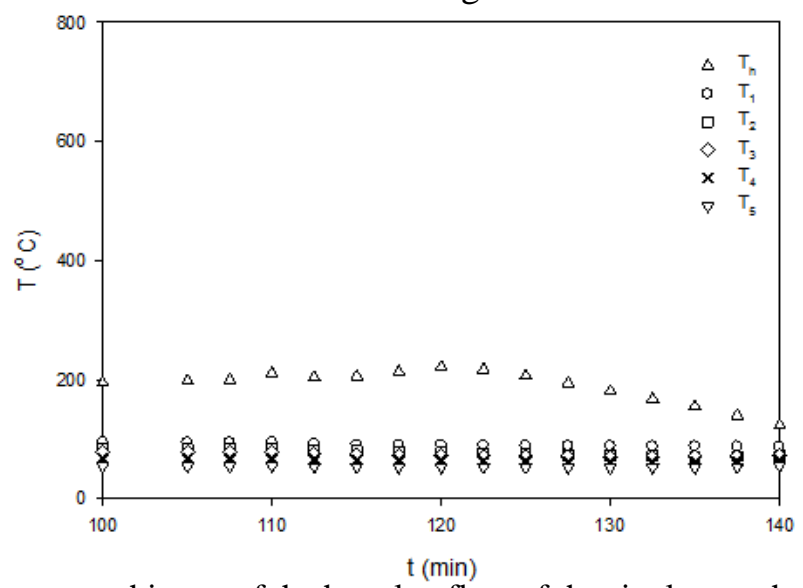

Fig. 10. Temperature history of the hot plug flow of the single gas phase (fluidizing air)

Figure 11 shows the temperature history for the first trial of combustion start-up. The fluidized bed was a mixture of $4 \mathrm{~kg}$ inert sand particles $(-0.705+0.5 \mathrm{~mm})$ and $1 \mathrm{~kg}$ petroleum coke fuel particles $(-10.0+5.0 \mathrm{~mm})$. The bed mixture was wetted with kerosene liquid fuel to support the combustion process. The heating-up of the bed mixture was achieved for a period of 127 minutes using preheated fluidizing air. The results of the first 100 minutes of the heating-up period were truncated as they are less significant. The average bed temperature shows an increase from a value of $46{ }^{\circ} \mathrm{C}$ to a value of $51{ }^{\circ} \mathrm{C}$ during the remaining 27 minutes of the heating-up period. Thus, the heating-up of the fluidized bed was performed with an average slow rate of $5 / 27=0.19^{\circ} \mathrm{C} / \mathrm{min}$. The process of combustion startup was performed by the aid of ignited $1 \mathrm{~kg}$ corncobs charge with average particle size of 10 $\mathrm{mm}$. The ignited charge was introduced to the bed mixture at the end of the heating-up period. This step of start-up process was accompanied, as shown in Fig. 11, with an average rapid heating rate of $57 / 3=19^{\circ} \mathrm{C} / \mathrm{min}$. The increase of the bed mixture (inert material + fuel) temperature due to the ignited corncobs particles was expected to continue reaching an ignition value of about $600^{\circ} \mathrm{C}$. This bed temperature is high enough for petroleum coke fuel particles to ignite and start combustion inside the inert sand particles. Unlikely, the results show nearly constant average bed temperature at a value of $110{ }^{\circ} \mathrm{C}$ during the period of the last 10 minutes of the plots in Fig. 11. This temperature value is much lower than the required ignition temperature. The low constant average values of bed temperature attained in the present trial of combustion start-up, reveal that the ignited corncobs particles were extinguished within the stated period of the last 10 minutes of the plots in Fig. 11. The event of extinguishing can be attributed to the combustion kinetics of the corncobs particles together with their low calorific value, as well as their small quantity. As a result, the trial of combustion start-up was stopped at the moment of 140 minutes, and the bed was cooled using large flow rate of cold fluidizing air. 


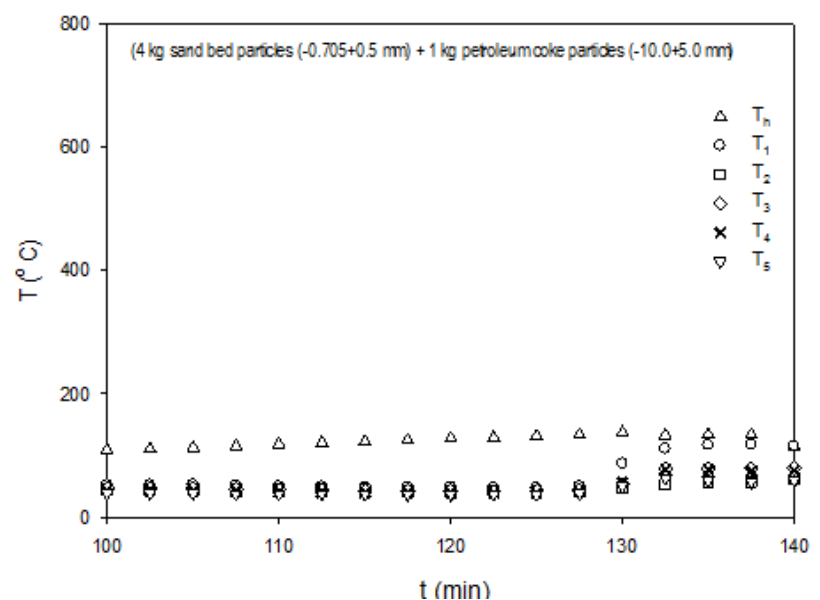

Fig. 11. The temperature history during the first trail of combustion start-up

Figures 12-14 show the results of the temperature histories representing the successful second trial of combustion start-up. The trial was performed within a total period of more than 200 minutes (3.5 hours). The fluidized bed was a mixture of $2 \mathrm{~kg}$ inert sand particles $(-0.705+0.5 \mathrm{~mm}), 1 \mathrm{~kg}$ petroleum coke fuel particles $(-10.0+5.0 \mathrm{~mm})$, and $0.5 \mathrm{~kg}$ corncobs particles with average size of $10 \mathrm{~mm}$. Based on the discussion of the results shown in Fig. 11, a search for better conditions of the combustion start-up was carried out. It was found that better conditions of start-up are associated with the aid of ignited charcoal instead of the previously used ignited corncobs. A $2 \mathrm{~kg}$ of ignited charcoal fuel particles $(-10.0+5.0 \mathrm{~mm})$ was chosen for its combustion characteristics superior to that of the previously used corncobs particles. Figure 12 shows the results for the heating-up of the bed mixture. It was achieved in the first 150 minutes using preheated fluidizing air. As was done with Fig. 11, the significant part of the bed temperature history was plotted only for the period of 40 minutes within the time interval from 110 minutes to 150 minutes. The plots show similar tendency of slow heating rate with an average value of $10 / 40=0.25$ ${ }^{\circ} \mathrm{C} / \mathrm{min}$. This value is somewhat large compared with the average heating rate value of 0.19 ${ }^{\circ} \mathrm{C} / \mathrm{min}$ found in Fig. 11. This is due to mainly the smaller heat capacity of the bed mixture in the present trial compared with that of Fig. 11. The process of combustion start-up was performed by introducing the ignited charge of charcoal particles to the bed mixture at the end of the heating-up period. The start-up process was accompanied, as shown in Fig. 13, with a rapid increase in the bed temperatures up to $730{ }^{\circ} \mathrm{C}$ which is above the required ignition value for the main bed fuel $\left(600^{\circ} \mathrm{C}\right)$. This situation indicates that the combustion start-up was successful and the combustion of the main fuel (petroleum coke particles) of the bed mixture could be achieved and continued raising the whole bed to much higher temperatures compared with those in Fig. 11. Figure 14 shows the results for the last stage of the combustion start-up process. The plots of the figure indicate continuous decrease in the average fluidized bed temperature due to the consumption of the burning fuel. This temperature decrease was also caused by introducing cold fluidizing air in order to end the present combustion start-up trial. Values of expanded bed height $L_{f}$ for the high temperatures shown in Figs 13-14, were estimated using the trends of Fig. 9. The expanded bed height $L_{f}$ was mostly found to cover the first three thermocouples indicating fluidized bed temperature values of $T_{1}, T_{2}$, and $T_{3}$. The other two thermocouples were predicted to indicate the gas phase temperatures $T_{4}$ and $T_{5}$ in the EFBC freeboard region. Keeping in 
mind this situation together with the transient nature of batch combustion, one can clearly find that the fluidized bed temperature is nearly uniform. The uniformity of the bed temperature indicates that the bed solids appear to be well-mixed and combustion occurs at high efficiencies. Moreover, the bed temperature uniformity is accompanied by bed temperature values which are much lower than those of known flame temperatures (up to $1200^{\circ} \mathrm{C}$ ) found in conventional combustion. The high flame temperatures usually cause the oxidation of nitrogen gas found in the combustion air resulting in the severe NOx pollutants. Consequently, this clearly shows the environmental advantage of fluidized bed combustion in reducing the atmospheric air pollution due to NOx pollutants.

Heat transfer from the high temperature fluidized bed to the immersed cooling coil was investigated during the hot flow and combustion tests. This was done by considering the thermal energy balance for the cooling water and the fluidized bed, together with the convective heat transfer to the cooling coil. The resulting equations were applied to the measured bed and cooling water temperatures in order to estimate an average value for the bed-to-cooling coil heat transfer coefficient $h_{b}$. The high values of the coefficient $h_{b}$ were compared with those for pure single-phase (hot air) gas flow. To achieve this task, the gas temperatures shown in Fig. 10 were employed together with the cooling water temperatures to estimate average comparative values for gas-to-cooling coil heat transfer coefficient $h_{g}$. Estimated average values of the bed-to-cooling coil heat transfer coefficient $h_{b}$ as much as $350 \mathrm{~W} / \mathrm{m}^{2} . \mathrm{K}$ were obtained at average bed temperatures up to $500{ }^{\circ} \mathrm{C}$. This result is in good agreement with the previously reported findings [6,7]. Moreover, the estimated $h_{b}$ values were found to be much larger (nearly 6 times) as compared with the estimated average $h_{g}$ value of $65 \mathrm{~W} / \mathrm{m}^{2} . \mathrm{K}$. This result is typical of the fluidized bed confirming the advantage of high values for the bed-to-immersed cooling coil heat transfer coefficients. Beside the abovediscussed results obtained for the hot flow and combustion tests, an inspection was done for the main functions of the various facility items and EFBC components. The inspection included possible problems related to assembly, operation, and maintenance. The following important findings were confirmed as a result of this inspection task:

- Ability of the various EFBC components to withstand thermal loads and hot spots.

- Security of the EFBC facility against exhaust gases leakage problems.

- Easy assembly, disassembly, cleaning, and maintenance of the EFBC facility items and components.

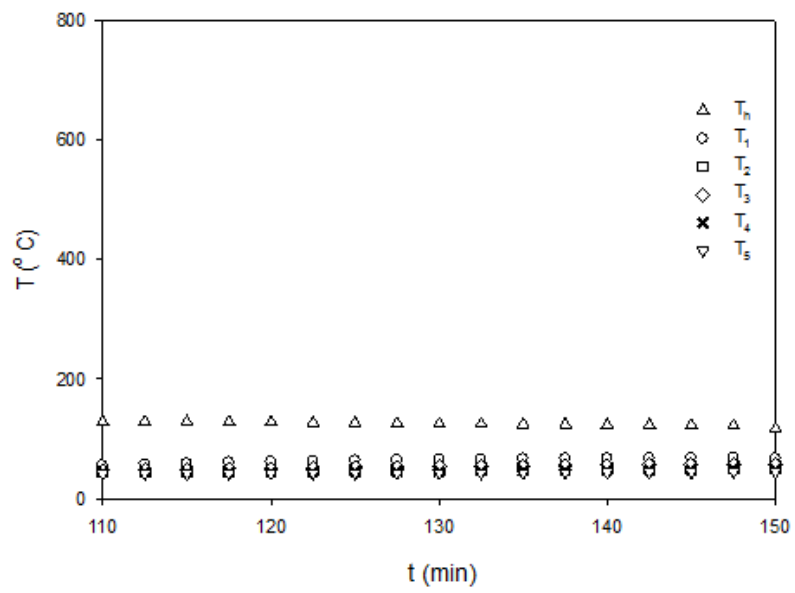

Fig. 12. The temperature history during the heating up period in the second trail of combustion start-up 


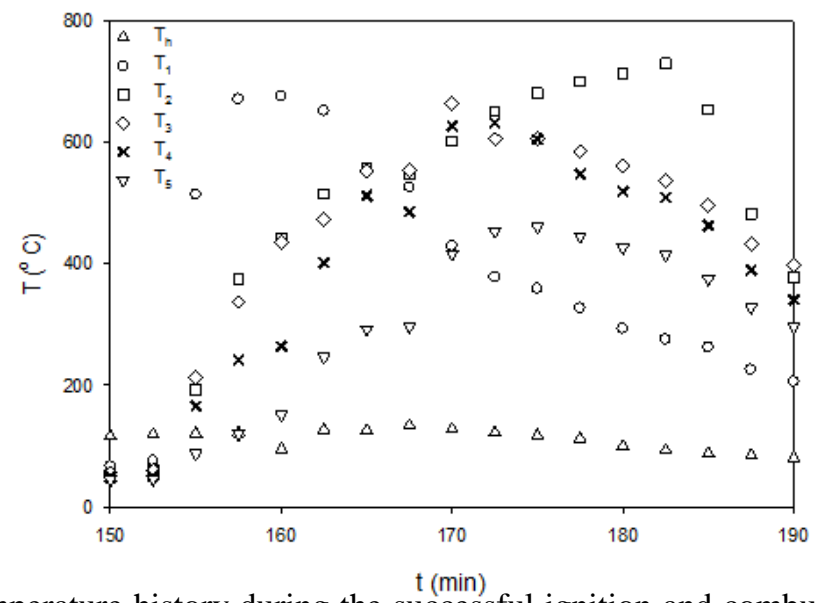

Fig. 13. The temperature history during the successful ignition and combustion of the fluidized bed fuel in the second trail of combustion start-up

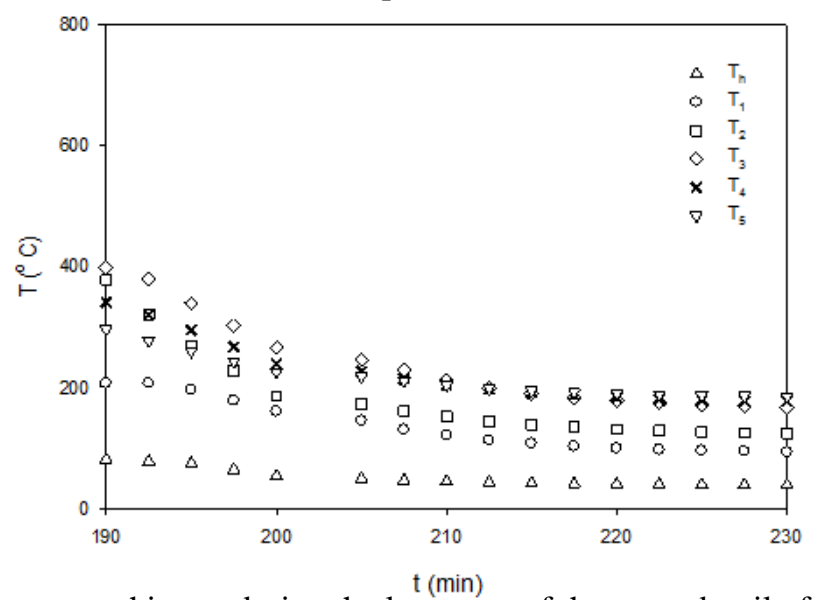

Fig. 14. The temperature history during the last stage of the second trail of combustion start-up

\section{Conclusions}

An experimental fluidized bed combustor (EFBC) with batch feeding of solid fuels has been designed, manufactured, and erected with its facility items in the Combustion Laboratory of Department of Mechanical Engineering, Assiut University. The EFBC facility items including fluidizing air compressors, piping, and heaters are necessary for the EFBC operation. The experimental EFBC has been designed to operate in the bubbling atmospheric mode of the fluidized bed. Characterization tests of the EFBC facility have been carried out using 50 hours-total duration experimental runs. They are grouped as cold flow testes, and hot flow and combustion tests. The results of these tests have confirmed the existence of the basic fluidization characteristics inherent to controlled fluidized bed hydrodynamics, heat transfer, and combustion of solid fuels. Based on the discussion of the obtained results, it is expected that the EFBC characterizations have been successfully demonstrated in the present research work. According to characterization tests, conclusions have been reached that the fluidizing air flow was reproducible with no appreciable leakage along different piping and EFBC facility connections. Moreover, good findings have been confirmed regarding assembly, disassembly, cleaning, and maintenance of the EFBC facility items and components. In addition to these findings, the EFBC components 
Hamdy M. Shafey et al., Characterization of an experimental facility for bubbling fluidized .......

have shown good ability to withstand thermal loads and hot spots, and acceptable security against exhaust gases leakage problems.

\section{Acknowledgments}

The authors would like to thank all persons working in the Faculty of Engineering Workshop, for their valuable help in manufacturing the experimental facility of the present work. In addition, the authors introduce their thanks and appreciation to all operators of the Mechanical Power Engineering laboratories contributing much to the present work. Among them the authors would like to express their deep thanks and gratitude to the chief technician Abd El-Wahid M. Abd El-Salam of the combustion laboratory for offering his good experience and sincere efforts.

\section{REFERENCES}

[1] H. M. Shafey, L. T. Fan, A. A. Abdellatif, A. S. Huzayyin, and I. S. Taha, "Clean heat and power generation and energy saving using fluidized bed technology," Grant FRCU-830216, Egyptian American Linkage Projects, report No. 1, Assiut, Egypt, 1984.

[2] H. M. Shafey, A.S. Huzayyin, "Suitability of Waste-Derived Fuels in Egypt for FluidizedBed Combustion," Proc. of First National Conf. on Environmental Studies and Research, Cairo, Egypt, 1988, pp. 611-621.

[3] H. M. Shafey, I. S. Taha, A. S. Huzayyin, "Computer-aided simulation of fluidized bed combustor," Analysis and Design of Energy Systems: Computer-Aided Engineering, ASME, 10(1), 1989, pp. 42-52.

[4] F. M. Nakhla, "Utilization of Maghara coal for energy development and metallurgical coke", Energy Research Center, Fac-Eng. Cairo Univ, 1990.

[5] D. B. Henschel, "The US environmental protection agency program for environmental characterization of fluidized-bed combustion systems." Proceedings of the $4^{\text {th }}$ Int. Conference on Fluidized-Bed Combustion, Washington, p.461, December 9-11, 1975.

[6] D. Geldart, "Gas fluidization technology", John Wiley \& Sons, New York, 1986.

[7] H. M. Shafey and I. S. Taha, "Experimental study on a bench-scale batch-type fluidized-bed combustor for energy production from waste-derived fuels," Energy, 17(4), 1992, pp. 331-338.

[8] G. Hetsroni, "Handbook of multiphase systems." Hemisphere Pub. Corp.; New York, 1982.

[9] M. Radovanović, "Fluidized bed combustion," Hemisphere Pub. Corp.; New York, 1986.

[10] D.Kunii, , and O. Levenspiel, "Fluidization Engineering," John Wiley \& Sons, New York, 1969.

[11] S. C. Saxena and C. K. Jotshi, "Fluidized-bed incineration of waste materials," Prog. Energy Combust. Sci., 20, 1994, pp. 281-324.

[12] E. J. Anthony, "Fluidized bed combustion of alternative solid fuels; status, successes and problems of the technology," Prog. Energy Combust. Sci., 21, 1995, pp. 239-268.

[13] S. Yavuzkurt, C. Gutfinger, J. Dayan, "Fluidized Combustion of Oil Shale," in "Fluidization," J. R. Grace, J. M. Matsen (Eds.), Plenum Press, New York, 1980, pp. 143-150.

[14] H. R. Howind, J. Deinert, Mittmann, H. Kroger, K. Schugerl, "Fluidized Bed Combustion of Lignite," in "Fluidization," D. Kunii, R. Toei (Eds.), Kashikojima, Japan, 1983, pp. 411-418.

[15] D. M. Albertson,"Design characteristics of a 12 MW AFB power station firing agricultural wastes," $10^{\text {th }}$ Int. FBC Conf., San Francisco, USA, 2, 1989, pp. 647-652.

[16] H. M. Shafey, M. A. Doheim, M. A. Al-Shagdari, M. S. Ahmed, and A. A. Abdellatif, "An Experimental study of the treatment of aluminum-cell gases for pollution control using fluidized-bed technology," Materials and manufacturing processes, 16(5), 2001, pp. 655-671.

[17] K.V.N. S. Rao, "Combustion studies of sawdust in a bubbling fluidized bed," The $12^{\text {th }}$ International Conference on Fluidization - New Horizons in Fluidization Engineering, pp. 945-952, 2007. 
[18] S. Suranani and V. R. Goli, "Fuel particle size effect on performance of fluidized bed combustor firing ground nutshells," International Journal of Chemical Engineering and Applications, 3(2), 2012, pp. 147-151.

[19] S. Suranani and V. R. Goli, "Combustion of agro-waste in a fluidized bed for heat recovery," International Conference on Chemical, Environmental and Biological Sciences (ICCEBS'2012), Penang, Malaysia, 2012, pp. 78-82.

[20] W. Jerzak, Z. Kalicka, E. Kawecka-Cebula, and M. Kuźnia, "Comparison of hazelnut and peanut shells combustion in bubbling fluidized-bed combustor," Energy Sources, Part A: Recovery, Utilization, and Environmental Effects, 38(15), 2016, pp. 2272-2281.

[21] K. Oshita, K. Kawaguchi, M. Takaoka, K. Matsukawa, T. Fujimori, and T. Fujiwara, "Emission and control of $\mathrm{N}_{2} \mathrm{O}$ and composition of ash derived from cattle manure combustion using a pilot-scale fluidized bed incinerator," Environmental Technology, 37(4), 2016, pp. 439-445.

[22] A. T. Atimtay, U. Kayahan, A. Unlu, B. Engin, M. Varol, H. Olgun, and H. Atakul, "Cofiring of pine chips with Turkish lignites in $750 \mathrm{~kW}$ th circulating fluidized bed combustion system," Bioresource Technology, 224, 2017, pp. 601-610.

[23] H. M. Shafey, L. T. Fan, A. A. Abdellatif, A. S. Huzayyin, and I. S. Taha, "Clean heat and power generation and energy saving using fluidized bed technology," Grant FRCU-830216, Egyptian American Linkage Projects, report No. 6, Assiut, Egypt, 1989.

[24] H. M. Shafey, "Investigation of grid region enhancement of heat and mass transfer in a fluidized-bed combustor," Bulletin of the Faculty of Engineering, Assiut University, 23(1), 1995, pp. 51-66. 


\section{فصص خصائص مجموعة تجهيزات معملية لتشغيل حارق طبقة مميعة في طور الفقاعات}

الملخص:

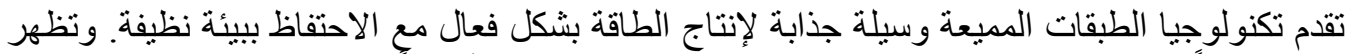

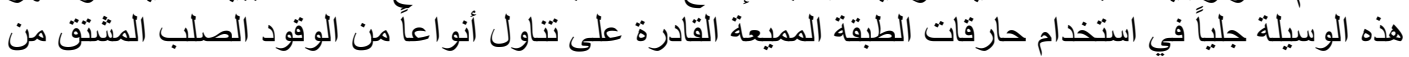

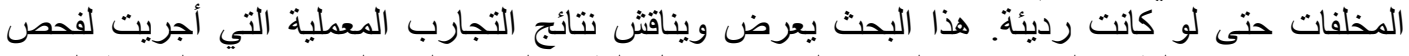

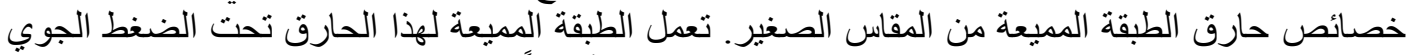

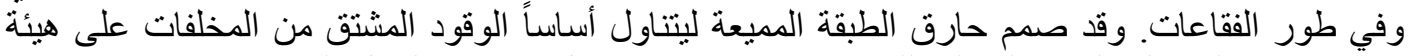

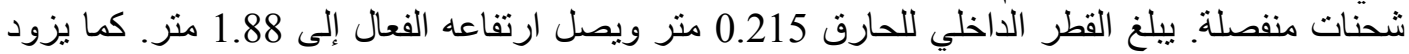

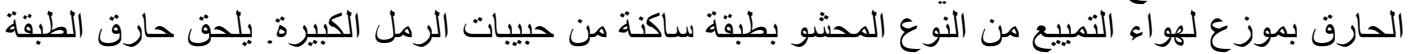

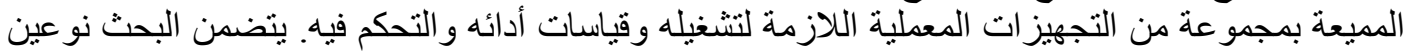

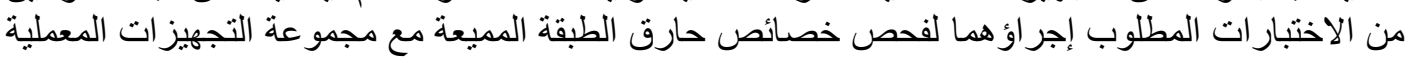

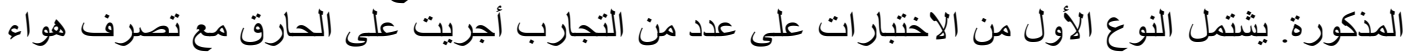

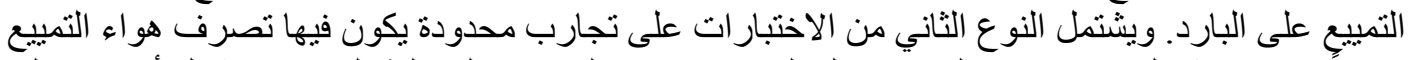

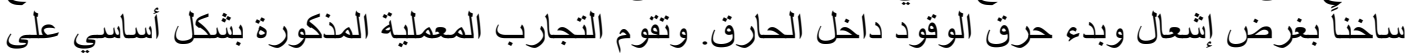

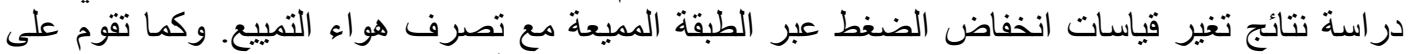

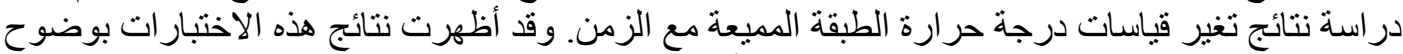

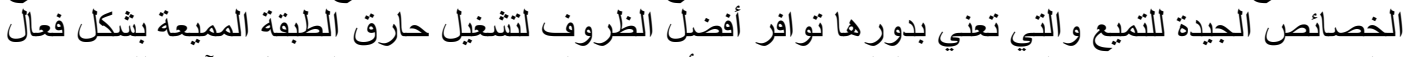

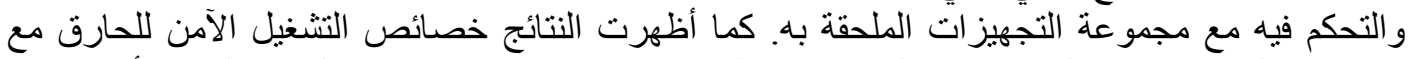

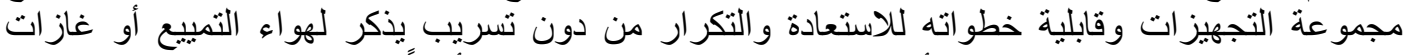

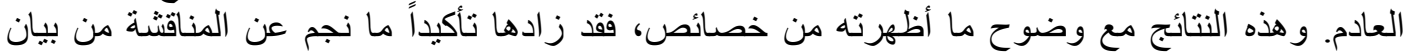
انتظام درجة حر ارة الطبقة المميعة بشكل مقبول. هذا بالإضافة إلى ما تضمنته المناقشة من قيم عالية مقدرة لمعامل انتقال الحرارة بين الطبقة الممبعة وملف التبريد. 